\title{
The Perceived Motivational Climate in Sport Questionnaire: Construct and Predictive Validity
}

\author{
Mary D. Walling, Joan L. Duda, and Likang Chi \\ Purdue University
}

\begin{abstract}
The purpose of this study was to further examine the construct and predictive validity of the Perceived Motivational Climate in Sport Questionnaire or PMCSQ. Young athletes $(N=169, M$ age $=14.2 \pm 1.94$ years $)$ on teams competing in an amateur international competition completed questionnaires measuring perceived motivational climate, the degree of worry experienced while participating, and team satisfaction. Results of a confirmatory factor analysis indicated an acceptable fit of the data with the hypothetical measurement model. In terms of the predictive utility of the PMCSQ, perceptions of a mastery climate were positively related to satisfaction with being a member on the team and negatively associated with performance worry. In contrast, perceptions of a performance climate were positively associated with concerns about failing and the adequacy of one's performance and negatively correlated with team satisfaction. Future directions in terms of instrument development and research on motivational climate in the sport setting are presented.
\end{abstract}

Key words: goal perspectives, confirmatory factor analysis

A universal goal of youth sport is to foster feelings of achievement and enjoyment among young participants. Central to the accomplishment of this aim is the necessity to understand the factors influencing young athletes' perceptions of success and sport experiences per se. An awareness of the information youth sport athletes use to interpret sport success has tremendous implications for coaches interested in motivating young athletes and maximizing their athletic involvement.

A foundation of research has been conducted and offers insight into the motivational patterns of participants in sporting environments. Based on goal perspective theory (Nicholls, 1984, 1989), this literature indicates that there are two major goal states operating in achievement situations, namely task and ego involvement. These two goal perspectives reflect different ways that individuals

M.D. Walling, J.L. Duda, and L. Chi are with the Department of Health, Kinesiology, and Leisure Studies at Purdue University, Lambert 113, West Lafayette, IN 47907. 
perceive themselves to be successful in sport and other achievement domains. When task-involved, individuals experience success when they try hard and improve their performance. In contrast, when ego-involved, individuals perceive success when their performance compares favorably to others.

According to goal perspective theory, people have a preference for adopting particular goal perspectives (i.e., they differ in their degree of task and/or ego orientation). The Task and Ego Orientation in Sport Questionnaire was developed to measure individual differences in the tendency for task- and ego-involved states in the athletic setting (Duda, 1989; Duda \& Nicholls, 1991). Investigations in sport and physical activity environments have linked a task orientation with athletes reporting greater intrinsic motivation, particularly in terms of increased levels of enjoyment and exerted effort and in terms of greater anticipation for continued participation in the future (Duda, Chi, Newton, Walling, \& Catley, in press; Walling, Duda, \& Crawford, 1992). In addition, task-involved athletes have been found to be more likely to endorse sportsmanlike behaviors, and to believe that success is achieved through effort and hard work (Duda \& Nicholls, 1992; Duda, Olson, \& Templin, 1991). In contrast, an ego orientation has been associated with greater depression and less reported enjoyment after a loss, and greater prematch somatic and cognitive anxiety (Boyd, Callaghan, \& Yin, 1991; Duda, Newton, \& Chi, 1990). In addition, ego orientation has been linked to the belief that success stems from the possession of high ability (Duda, Fox, Biddle, \& Armstrong, 1992; Duda \& Nicholls, 1992; Duda \& White, 1992; Newton \& Duda, 1992).

Besides individual differences in goal orientations, goal perspective theory suggests that there are other important factors which impact whether a person is task- or ego-involved at any one point in time. These additional influences include the developmental stage of the individual and the situation at hand (Duda, 1987; Nicholls, 1990; Nicholls \& Miller, 1984).

With respect to the latter, situations can place emphasis on task- or egoinvolved goals. It is presumed that the prevailing situational goal structure or motivational climate will influence the goals people adopt as well as their perceptions, attitudes, and behaviors in achievement-related activities such as school and sport.

Ames $(1984,1992)$ has been particularly interested in the study of motivational climate in the academic setting. She and her colleague (Ames \& Archer, 1988) were the first to develop a questionnaire to tap students' perceptions of the goal perspective operating in their classrooms. Ames and Archer's initial work indicated that, in the view of students, classroom environments can be characterized as more or less task- or ego-involving. These two climates were labeled mastery- and performance-oriented, respectively. Ames and Archer (1988) also found that high school students' perceptions of the classroom goal structure predicted important motivational indices. Specifically, perceptions of a mastery or task-involving climate were related to the reported use of more effective learning strategies, a preference for more challenging tasks, more positive attitudes towards the class, and the belief that effort leads to success. These findings have been reproduced with samples of elementary school children (Ames, 1992).

Seifriz, Duda, and Chi (1992) replicated and extended the work of Ames and Archer (1988) in the sport domain. They developed an assessment of perceptions of the motivational climate in the sport setting, conducting initial psychometric 
work on the Perceived Motivational Climate in Sport Questionnaire (PMCSQ). Further, this study examined the relationship of perceived motivational climate to high school athletes' enjoyment of their sport experience and beliefs about the causes of success. In this research, questionnaires were administered midseason to members of nine boys' high school basketball teams.

Seifriz et al. (1992) found that the high school athletes could distinguish between mastery-oriented (or task-involving) and performance-oriented (or egoinvolving) team climates. On teams that were deemed more mastery-focused, the athletes felt that trying hard was rewarded, players were encouraged by the coach, and every player had an important role on the team. In terms of a performance-oriented climate, the athletes perceived that teammates try to outdo each other, players are punished for mistakes, and recognition is limited to only a few talented players.

Importantly, these perceptions of the team climate predicted achievementrelated perceptions and affective responses (Seifriz et al., 1992). Athletes perceiving a mastery-oriented climate reported increased levels of enjoyment and tended to believe that effort leads to success. In contrast, athletes who perceived a performanceoriented or ego-involving team climate reported decreased levels of enjoyment and expressed the belief that possessing superior ability results in success.

Drawing from the work of Seifriz and his colleagues, the purpose of this study was twofold. First, the present research further examined the construct validity of the Perceived Motivational Climate in Sport Questionnaire (PMCSQ) among a sample of young adolescents via the use of confirmatory factor analysis. Second, to provide further information of the predictive validity of the PMCSQ, the relationship of perceived motivational climate to athletes' performance-related worry and satisfaction with being a member of one's team was determined.

It was hypothesized that players were more likely to be satisfied with their experiences on their team and to have lower performance worry when the team climate was more mastery-oriented. A mastery-oriented climate focuses on effort and personal improvement, factors over which these young participants have control. Therefore, it is expected that these athletes should feel more successful and satisfied about their participation in task-involving team environments and less concerned about poor performance.

It was also predicted that performance-related worry was more likely to be reported among athletes who perceived their team climate to be more performance-oriented or ego-involving. Team satisfaction was hypothesized to negatively relate to perceptions of a performance-oriented team atmosphere. Young participants on teams with a performance-oriented climate must perform favorably compared to their peers in order to feel successful. Performance outcome (and/ or the demonstration of superior ability) is less under the volitional control of the athlete. This relative lack of control and focus on the normative adequacy of one's competence level should result in greater personal concern about one's athletic performance and less satisfaction with being part of a team.

\section{Method}

\section{Subjects}

Subjects were 169 young female $(n=83)$ and male $(n=86)$ athletes from a large Midwestern city who were competing in an international amateur 
competition. Their mean age was $14.2 \pm 1.94$ years and they were participating in the following team sports: baseball, basketball, softball, and soccer. A breakdown of the sample by race/ethnicity revealed that $73 \%$ of the subjects were white, $26 \%$ were black, and the remaining $1 \%$ were of other racial/ethnic backgrounds.

\section{Procedures}

After securing permission from the organization sponsoring the competition, coaches were contacted to gain their cooperation in allowing their athletes to participate in the present research. Parents provided their permission to the sponsoring organization in terms of their children's participation in the competition as well as research related to this involvement. The athletes were told that their participation in the study was voluntary and were assured that their responses would remain anonymous. Because of the nature of the questions posed, it was deemed important to administer the questionnaires in the absence of the coach. The athletes completed the questionnaires while traveling to Canada in a group setting. The questionnaires were administered by trained assistants.

\section{Measures}

The questionnaire completed by the athletes consisted of three sections:

Part 1: Perceived Motivational Climate in Sport Questionnaire. The players' perceptions of the degree to which their respective team's motivational climate was characterized by mastery and performance goals were measured with the Perceived Motivational Climate in Sport Questionnaire (PMCSQ). Initial information on the validity and reliability of the instrument is presented in the Seifriz et al. study (1992). Their exploratory factor analyses of the PMCSQ revealed two predominant dimensions. Specifically, the instrument was found to be comprised of a mastery (task-involving) and performance (ego-involving) climate scale. Both scales demonstrated acceptable internal reliability with alpha reliability coefficients of .80 and .84 , respectively. The correlation between the two scales was -.26 .

The stem "'On this team ...'" preceded each item and athletes responded to the items on a 5-point Likert type scale ranging from 1 (strongly disagree) to 5 (strongly agree). The performance scale consisted of 12 items (e.g., "'On this team, the coach gives most of his attention to the 'stars' ''), and the mastery scale included 9 items (e.g., "On this team, trying hard is rewarded"). Instructions to the athletes stressed the importance of responding to the questions in terms of their feelings about the particular team at hand, and not overall feelings relating to the potential myriad of teams they have competed on in the past.

Part 2: Performance Worry. An eight-item measure of performance worry was employed based on previous research concerning the predictors of competitive anxiety among young athletes (Gould, Horn, \& Spreeman, 1983). Athletes responded to the items on a 5-point Likert type scale ranging from 1 (strongly disagree) to 5 (strongly agree). The stem "On this team ..." preceded each item, and athletes responded to the items with respect to their experiences on their particular teams. A sample item included "On this team, I worry about performing up to my ability."' The item responses were summed for a total score reflecting an athlete's tendency to experience cognitive worry in terms of his or her fear of failure and feelings of inadequacy. 
Part 3: Team Satisfaction. A three-item measure of the athletes' satisfaction with being a member of their respective teams was developed by the authors. Athletes indicated on a scale of 1 (strongly disagree) to 5 (strongly agree) the extent to which they were pleased to be playing on their particular teams. A sample item included "I'm very glad that I have played on this team this year."

\section{Results}

\section{Confirmatory Factor Analyses}

A confirmatory factor analysis was conducted to test the construct validity of the Perceived Motivational Climate in Sport Questionnaire. The advantage of using confirmatory factor analysis is that it provides information indicating how well the data in total fits the proposed hypothetical model. Thus, the first step in conducting a confirmatory factor analysis involves the specification of a hypothesized measurement model of the Perceived Motivational Climate in Sport Questionnaire. Drawing from the work of Seifriz et al. (1992), a model was proposed (see Figure 1). The circles represent the two climate scales (or latent variables) and the boxes represent the items designed to measure those scales. In addition, the lambda $(\lambda)$ represents the variance accounted for by the item loading, whereas the delta $(\delta)$ represents the measurement error of each item.

Results of the confirmatory factor analysis are presented in Figure 2. The four indices considered to test the goodness of fit of the model and the data were the following: the chi-square value, the chi-square to degrees of freedom ratio, the goodness of fit index (GFI), and the root mean square residual (RMSR). The chi-quare statistic tests the hypothesis that the model fits the data. The observed significant chi-square result indicated that the hypothesized model and the sample data were significantly different. However, the chi-square statistic is frequently significant since the test statistic is quite strict (Fassinger, 1987; Joreskog, 1969). Because of this, other indices are often considered since a relatively good fit may be evident in spite of a significant chi-square value. For example, the observed ratio of chi-square and degrees of freedom equaled 2.93. Although there are no clearly established rules, a ratio of three or less indicates an acceptable fit of the model with the data (Joreskog, 1969).

The GFI is a measure of the relative degree to which the variances and covariances are jointly accounted for by the model. The observed GFI of .770 suggests an acceptable fit of the data with the model. However, the GFI value of .770 could be higher, suggesting that there is room for improvement with respect to capturing the hypothetical measurement model.

The root mean square residual (RMSR) is a summary measure which compares the model estimate of the correlation matrix with the observed sample population correlation matrix. If the hypothesized model fits the population perfectly, the RMSR would be zero. An RMSR under .05 is considered to be excellent, but a value between .05 and .10 is typically considered acceptable (Rupp \& Segal, 1989). The interfactor correlation ( $\Phi)$ was also examined and was found to be negative and moderately low.

The modification index measures the predicted decrease in the chi-square value when a single constraint is relaxed and the model is reestimated (Joreskog \& Sorbom, 1989). Examination of the modification indices for theta delta $\left(\theta_{\delta}\right)$ 


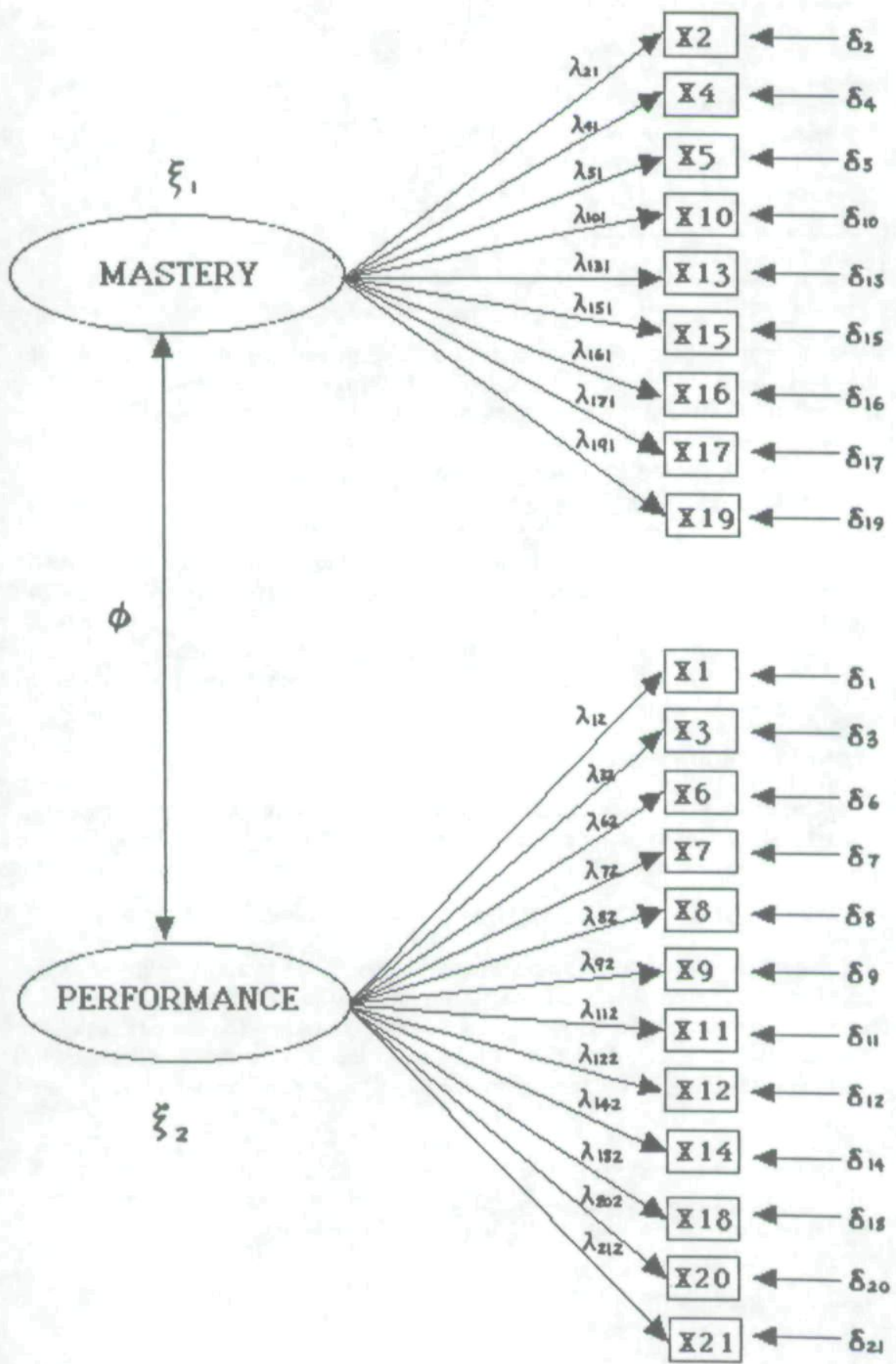

Figure 1 - The measurement model for the 21-item Perceived Motivational Climate in Sport Questionnaire. 
Chi-square with $188 d f=550.75(p<.0001)$

Ratio $=\chi^{2} / d f=2.93$

Goodness of fit index $=.770$

Adjusted goodness of fit index $=.717$

Root mean square residual $=.108$

Interfactor correlation $=-.30(t=-3.45, p<.01)$

Figure 2-Results of the confirmatory factor analysis.

revealed several high residuals caused by the measurement errors among the observed items within each of the scales. High residuals indicate some degree of correlation between the measurement errors of particular items within a scale. Since it was reasonable that some of the measurement errors within a scale would be correlated, a second confirmatory analysis was run. ${ }^{1}$ This analysis set free 17 pairs of theta deltas, or allowed certain measurement errors within a scale to covary with one another (Joreskog \& Sorbom, 1989).

The results of the second confirmatory factor analysis are presented in Figure 3. Setting free particular theta deltas significantly improved the overall goodness of fit of the data with the model, particularly in terms of the ratio of chi square and degrees of freedom, and the goodness of fit index. Once again, a moderately low negative interfactor correlation between the mastery and performance scales was observed.

\section{Internal Reliability of the PMCSQ Scales}

Cronbach (1951) alpha reliability coefficients were calculated for each of the two scales. Alphas of .82 and .80 were found for the mastery and performance scales, respectively.

\section{Predictive Validity of the PMCSQ}

The measures of performance worry and team satisfaction employed exhibited acceptable internal reliability with alpha coefficient values of .76 and .63 , respectively. Correlations between these two variables and the climate scales are presented in Table 1. Perceptions of a task-oriented or mastery climate were significantly and positively related to team satisfaction and negatively correlated

\footnotetext{
Chi-square with $171 d f=346.14(p<.0001)$

Ratio $=\chi^{2} / d f=2.02$

Goodness of fit index $=.851$

Adjusted goodness of fit index $=.798$

Root mean square residual $=.091$

Interfactor correlation $=-.36(t=4.41, p<.01)$
}

Figure 3-Results of the confirmatory factor analysis with items set free. 
Table 1

\section{Simple Correlations Between the Mastery and Performance Climate Scales and the Cognitive/Affective Measures}

Performance
worry
Team

satisfaction

Mastery climate

Performance climate

$.39^{* * *}$

$-.26^{* * *}$

${ }^{*} p<.05 .{ }^{* *} p<.01 .{ }^{* * *} p<.001$.

with performance worry. In contrast, athletes who perceived an ego- or performance-oriented team climate reported significantly greater performance worry and less satisfaction with being members of those teams.

\section{Discussion}

One purpose of this study was to further examine the construct validity of the Perceived Motivational Climate in Sport Questionnaire by conducting confirmatory factor analyses. The findings based on this analysis supported the two-dimensional structure of the PMCSQ. In general, the results of the confirmatory factor analysis suggest an acceptable fit of the data with the hypothesized measurement model. In terms of examining the validity of psychological assessments, confirmatory factor analysis techniques have received minimal attention within the sport psychology literature. The present findings, however, compare favorably to those of other published studies in the field which have employed similar analyses (Chi \& Duda, 1992; Gill \& Deeter, 1988; McAuley, Duncan, \& Tammen, 1989; Weiss, Bredemeier, \& Shewchuk, 1985).

Of interest was the observed moderately low negative interfactor correlation which was revealed between the mastery and performance climate scales. In terms of the dispositional goal orientation measure (i.e., the Task and Ego Orientation in Sport Questionnaire), the task- and ego-orientation scales have been found to be orthogonal (Chi \& Duda, 1992; Duda, 1989; Duda et al., 1992; Stephens \& Bredemeier, 1992). It was not expected, however, that the two climate scales would be independent. That is, it would appear contradictory to be on a team where players are "encouraged to work on weaknesses"" and "punished for making mistakes," or where everyone "'has an important role" and "the coach gives most of his attention to the stars." Thus, the observed moderate negative correlation between the performance and mastery scales was not surprising.

The two confirmatory factor analyses provided important information relating to the nature and the structure of the climate instrument. Careful inspection of the results (such as the modification indices) suggested that there is potential for further improving the measure. Specifically, the modification indices for the measurement errors of the observed variables revealed a considerable amount of unexplained variance. In addition, the second confirmatory analysis in which the 
measurement errors of certain items were freed resulted in an improved goodness of fit of the model. It might be the case that the addition of subscales to the mastery and performance scales, respectively, would aid in accounting for greater unexplained variance in the model. Future refinement of the PMCSQ might stem from the testing of such a hierarchical model.

A second purpose of the present research involved examining the predictive value of the Perceived Motivational Climate in Sport Questionnaire. The results were in line with goal perspective theory and provided evidence for the predictive validity of the instrument. Specifically, athletes perceiving a task-involving climate indicated they felt greater satisfaction participating on their respective teams, and they experienced lower levels of performance worry. In contrast, athletes reported worrying more about their performance and being less satisfied with their teams when they perceived the climate was ego-involving.

Although there is no evidence currently to suggest cause and effect relationships, a pattern has emerged in terms of the psychosocial correlates of the PMCSQ. Results of the present study add to those of Seifriz et al. (1992) in that perceptions of a mastery climate have now been associated with greater reported exerted effort, greater enjoyment, greater satisfaction with one's team, lower performance worry, and the belief that success is achieved through trying hard. Findings from the two studies link perceptions of a performance climate to greater levels of worry, less satisfaction with being part of one's team, and the belief that ability leads to success. While additional investigation is needed to further verify these results, initial research would indicate that young athletes have much to gain from participating in a mastery-oriented environment in the sport domain. In contrast, participation on a team enshrouded by a performance-oriented climate seems to set the stage for short- as well as long-term motivational difficulties.

\section{Future Research Directions}

The present research examined athletes' perceptions of the team climate at one point in time. Future work should consider whether athletes' perceptions of the climate change over time (e.g., across a season and/or across seasons). In addition, longitudinal examination of how athletes' perceptions of the team climate relate to their cognitions, affective responses, and behaviors would result in valuable information.

Based on her research and the tenets of goal perspective theory, Ames (1992) has tested an intervention program to aid teachers in promoting a masteryoriented climate in their classrooms. The results of this longitudinal investigation revealed that students of teachers who received training maintained their levels of motivation throughout the school year. In contrast, the motivational level of the students in control classrooms decreased during the same time period.

There is a need for similar applied research in sport psychology. Present and future studies on the correlates of perceived motivational climate in sport can provide the empirical basis for such intervention work. Moreover, a valid and reliable assessment of perceived motivational climate could serve as a measure of the effectiveness of the situational manipulation in subsequent field experiments.

Finally, one attractive feature of goal perspective theory is that it reflects an interactionist approach to the study of motivation. That is, both characteristics of the person and the situation in which the person finds himself or herself 
are assumed to influence the individual's cognitive and affective reactions and behavioral patterns in that context. In the work of Seifriz et al. (1992), low (albeit significant) correlations between dispositional goal orientations and perceptions of the motivational climate were found. In future work, it would be interesting to determine the interplay between dispositional and perceived situationally induced goals on motivational processes. Specifically, investigation of the compatibility/ incongruence between dispositional goal orientations and perceptions of team climate, as well as the motivational consequences of such relationships would be intriguing.

\section{References}

Ames, C. (1984). Competitive, cooperative and individualistic goal structures: A motivational analysis. In R. Ames \& C. Ames (Eds.), Research on motivation in education: Student motivation (pp. 177-207). New York: Academic Press.

Ames, C. (1992). Achievement goals, motivational climate, and motivational processes. In G. Roberts (Ed.), Motivation in sport and exercise (pp. 161-176). Champaign, IL: Human Kinetics.

Ames, C., \& Archer, J. (1988). Achievement goals in the classroom: Students' learning strategies and motivation processes. Journal of Educational Psychology, 80, 260267.

Boyd, M., Callaghan, J., \& Yin, Z. (1991). Ego-involvement and low competence in sport as a source of competitive trait anxiety. Paper presented at the annual meeting of the North American Society for the Psychology of Sport and Physical Activity, Asilomar, CA.

Chi, L., \& Duda, J.L. (1992). Multi-sample confirmatory factor analyses of the Task and Ego Orientation in Sport Questionnaire. Manuscript submitted for publication.

Cronbach, L.J. (1951). Coefficient alpha and the internal structure of tests. Psychometrika, 16, 296-334.

Duda, J.L. (1987). Toward a developmental theory of achievement motivation in sport. Journal of Sport Psychology, 9, 130-145.

Duda, J.L. (1989). The relationship between task and ego orientation and the perceived purpose of sport among male and female high school athletes. Journal of Sport \& Exercise Psychology, 11, 318-335.

Duda, J.L., Chi, L., Newton, M., Walling, M., \& Catley, D. (in press). Task and ego orientation and intrinsic motivation in sport. International Journal of Sport Psychology.

Duda, J.L., Fox, K., Biddle, S.J.H., \& Armstrong. N. (1992). Children's achievement goals and beliefs about success in sport. British Journal of Educational Psychology, 62, 309-319.

Duda, J.L., Newton, M., \& Chi, L. (1990, May). The relationship of task and ego orientations and expectations on multidimensional state anxiety. Paper presented at the annual meeting of the North American Society for the Psychology of Sport and Physical Activity, University of Houston.

Duda, J.L., \& Nicholls, J.G. (1991). The Task and Ego Orientation in Sport Questionnaire: Psychometric properties. Unpublished manuscript.

Duda, J.L., \& Nicholls, J.G. (1992). Dimensions of achievement motivation in schoolwork and sport. Journal of Educational Psychology, 84, 290-299.

Duda, J.L., Olson, L.K., \& Templin, T. (1991). The relationship of task and ego orientation 
to sportsmanship attitudes and the perceived legitimacy of injurious acts. Research Quarterly for Exercise and Sport, 62, 79-87.

Duda, J.L., \& White, S.A. (1992). Goal orientations and beliefs about the causes of success among elite skiers. The Sport Psychologist, 6, 334-343.

Fassinger, R.E. (1987). Use of structural equation modeling in counseling psychology research. Journal of Counseling Psychology, 34, 425-436.

Gill, D., \& Deeter, T.E. (1988). Development of the sport orientation questionnaire. Research Quarterly for Exercise and Sport, 59, 191-202.

Gould, D., Horn, T., \& Spreeman, J. (1983). Sources of stress in junior elite wrestlers. Journal of Sport Psychology, 5, 159-171.

Joreskog, K.G. (1969). A general approach to confirmatory maximum likelihood factor analysis. Psychometrika, 34, 183-202.

Joreskog, K.G., \& Sorbom, D. (1989). LISREL 7: A guide to the program and applications (2nd ed.). Chicago: SPSS.

McAuley, E., Duncan, T., \& Tammen, V. (1989). Psychometric properties of the intrinsic motivation inventory in a competitive sport setting: A confirmatory factor analysis. Research Quarterly for Exercise and Sport, 60, 48-58.

Newton, M., \& Duda, J.L. (1992, April). Tennis is not a matter of life and death, it's much more important than that: The relationship between dispositional goal orientations and effort, importance, and interest among adolescent tennis players. Paper presented at the conference of the American Alliance of Health, Physical Education, Recreation, and Dance, Indianapolis, IN.

Nicholls, J.G. (1984). Conceptions of ability and achievement motivation. In R. Ames \& C. Ames (Eds.), Research on motivation in education: Student motivation (Vol. 1, pp. 39-73). New York: Academic Press.

Nicholls, J.G. (1989). The competitive ethos and democratic education. Cambridge, MA: Harvard University Press.

Nicholls, J.G. (1990). What is ability and why are we mindful of it? A developmental perspective. In R.J. Sternberg \& J. Kolligian, Jr. (Eds.), Competence considered (pp. 11-40). New Haven, CT: Yale University Press.

Nicholls, J.G., \& Miller, A.T. (1984). Development and its discontents: The differentiation of the concept of ability. In J. Nicholls (Ed.), Advances in motivation and achievement (Vol. 3, pp. 185-218). Greenwich, CT: JAI Press.

Rupp, M.T., \& Segal, R. (1989). Confirmatory factor analysis of a professionalism scale in pharmacy. Journal of Social and Administrative Pharmacy, 6, 31-38.

Seifriz, J., Duda, J.L., \& Chi, L. (1992). The relationship of perceived motivational climate to achievement-related affect and cognitions in basketball. Journal of Sport \& Exercise Psychology, 14, 375-391.

Stephens, D.M., \& Bredemeier, B.J. (1992, June). A tale of two theories: The relationship between Eccles' expectancy-value and Nicholls' goal orientation theories of achievement motivation. Paper presented at the annual meeting of the North American Society for the Psychology of Sport and Physical Activity, Pittsburgh.

Walling, M.D., Duda, J.L., \& Crawford, T. (1992). Goal orientations, outcome, and responses to youth sport competition among high/low perceived ability athletes. Manuscript submitted for publication. 
Weiss, M.R., Bredemeier, B.J., \& Shewchuk, R.M. (1985). An Intrinsic/Extrinsic Motivation Scale for the youth sport setting: A confirmatory factor analysis. Journal of Sport Psychology, 7, 75-91.

\section{Note}

'That is, we suspected that there might be systematic error due to interrelationships between particular items which comprise each of the scales (e.g., the items concerned with the emphasis on skill improvement which loaded on the mastery scale).

\section{Acknowledgments}

The authors gratefully acknowledge the assistance of Dr. Tom Crawford, U.S. Olympic Committee; and the National Institute for Fitness and Sport, Indianapolis, IN. The present study was a component of a larger investigation which was supported in part by a Lilly Endowment grant to the National Institute for Fitness and Sport.

Manuscript submitted: August 20, 1992

Revision received: December 6, 1992 
Copyright of Journal of Sport \& Exercise Psychology is the property of Human Kinetics Publishers. Inc. and its content may not be copied or emailed to multiple sites or posted to a listserv without the copyright holder's express written permission. However, users may print, download, or email articles for individual use. 